Elsevier required licence: (C) <2016>. This manuscript version is made available under the CC-BY-NCND 4.0 license http://creativecommons.org/licenses/by-nc-nd/4.0/

The definitive publisher version is available online at

[https://www.sciencedirect.com/science/article/pii/S0260691715005031?via\%3Dihub] 


\section{Plastic with personality: Increasing student engagement with manikins}

Tamara Power a,(Corresponding author), Claudia Virdun a, Haidee White a, Carolyn Hayes a, Nicola Parker ${ }^{\mathrm{b}}$, Michelle Kelly c, Rebecca Disler a, Amanda Cottle a

a Faculty of Health, University of Technology Sydney, Australia, $\mathrm{b}$ Institute for Interactive Media and Learning, University of Technology, Sydney ${ }^{\mathrm{C}}$ School of Nursing, Midwifery and Paramedicine, Curtin University, Perth, Australia

Background: Simulation allows students to practice key psychomotor skills and gain technical proficiency, fostering the development of clinical reasoning and student confidence in a low risk environment. Manikins are a valuable learning tool; yet there is a distinct lack of empirical research investigating how to enhance engagement between nursing students and manikins.

Objective: To describe student perspectives of a layered, technology enhanced approach to improve the simulation learning experience.

Educational Framework: Tanner's Model of Clinical Judgment underpins the entire curriculum. This study additionally drew on the principles of narrative pedagogy.

Intervention: Across ten teaching weeks, five separate case studies were introduced to students through short vignettes. Students viewed the vignettes prior to their laboratory class. In the labs, manikins were dressed in the props used in the vignettes.

Setting: The innovation was trialed in a second year core subject of a Bachelor of Nursing program in a large urban university in the autumn semester of 2014.

Data Collection and Analysis: Following ethics approval, students were emailed a participant information sheet. A focus group of nine students was held. The discussion was digitally recorded and transcribed verbatim prior to being subject to thematic analysis. Students' comments (143) about the vignettes in their standard subject specific student feedback surveys were also considered as data.

Results: Four themes were identified: Getting past the plastic; knowing what to say; connecting and caring; and, embracing diversity. The feedback indicated that these measures increased students ability to suspend disbelief, feel connected to, and approach the manikins in a more understanding and empathetic fashion.

Conclusions: In addition to achieving increased engagement with manikins, other advantages such as students reflecting on their own values and pre-conceived notions of people from diverse backgrounds were realized.

Introduction

Simulation has become an essential element of nursing education (Foronda et al., 2013). The range of different types of simulations utilized in nursing education can include standardized and simulated patients, task trainers, computer-assisted or virtual instruction, hybrids and role-play (McAllister et al., 2013). All of these simulation modalities can provide active learning opportunities for health professions students, foster development of clinical reasoning skills (Jensen 2013) and increase student confidence prior to clinical practice (Ricketts, 2011). Using simulation also allows students to practice key psychomotor skills and gain technical proficiency with no risk to patients (Cant and Cooper, 2010; Schiavenato, 2009).

Like medicine, nursing has embraced the use of manikins. The use of manikins in nursing has been considered particularly valuable because it can expose students to complex sets of physiological symptoms, allowing them to think critically and exercise decision-making skills (Shin et al., 2015; Yeun et al., 2015). Patients' backgrounds and social perspectives can be incorporated into complex case studies but there can be a disconnect when extending the context of the story into a simulation scenario where the manikin represents the patient. If the expectation is for students to engage in nurse-patient interactions and develop the nuances of professional practice, additional strategies to link the manikin with the patient's story and context are necessary. Yet there is a distinct lack of empirical research investigating the effectiveness of the full range of simulation modalities for student learning and development of clinical expertise in nursing (Schiavenato, 2009; Walton et al., 2011). 
A commonly reported issue is students struggling to suspend disbelief in clinical simulation scenarios (McAllister et al., 2013). Current manikins lack the physical characteristics of movement particularly facial expressions and the subtleties of human responses (Kameg et al., 2010). Students particularly find it difficult to talk to, and relate to a manikin authentically as a patient (Barry et al., 2012). Yet discussion in the literature regarding enhancing nursing student engagement with manikins is largely anecdotal. The commitment to the use of manikins in nursing education creates an urgency to explore and improve students' perception of their realism to develop methods for increasing engagement.

This paper reports upon a teaching and learning strategy that was designed to increase student engagement with manikins by incorporating audio-visual $(\mathrm{A}-\mathrm{V})$ patient vignettes. Audio-visual vignettes represent the introduction of virtual, standardized patients (Guise et al., 2012). In health care, vignettes, "also called trigger films" (McLain et al., 2012, p.S11), are short audio-visual representations of actors portraying patients and health professionals in clinical situations, which allow the viewer to watch a situation unfold. Vignettes may tell a complete story or end unresolved in order to stimulate discussion and decision making (McLain et al., 2012). Recently vignettes have been used to assess critical thinking in nursing students (Fero et al., 2010), evaluate registered nurses' assessment of pain (Al-Shaer et al., 2011), and anesthetic nurses' clinical performance after exposure to patient safety vignettes (McLain et al., 2012). The use of vignettes in this study was intended to extend the paperbased case studies already in use in the subject and imbue the manikins with a recognizable personality and personal history.

Previous research has indicated that $\mathrm{A}-\mathrm{V}$ vignettes are a highly effective teaching strategy. As online learning materials can be accessed repeatedly they are especially valued by students whose first language is not English (McConville and Lane, 2006). They are useful to illustrate diseases and conditions students may not have encountered during their clinical placements (Volandes, 2007); or caring for patients with challenging behaviors (McConville and Lane, 2006).

$\mathrm{A}-\mathrm{V}$ vignettes can provide nuanced and contextual information about patients with varying illnesses, socioeconomic and cultural back- grounds, behaviors and responses to care. Nurses interacting with patients can be modeled in the vignettes and then incorporated into class discussion to enhance student understanding of optimum nurse- patient communication and problem solving. The combination of A-V vignettes preceding work with manikins is a new approach to increase the context of the simulation experience, and therefore engagement with the clinical scenario and the manikin. This paper reports student perspectives of a layered, technology enhanced approach to improve the simulation learning experience.

Methods

\section{Context}

The innovation was trialed in Medical Surgical Nursing, a second year core subject of a Bachelor of Nursing program in a large urban Australian university in the first semester of 2014. This subject builds on students' previous clinical experiences to develop their critical application and judgment about nursing methods and practices for optimizing management of acute medical-surgical conditions in tertiary care settings. The student cohort is split between two semesters with an average of 450 students enrolled in the first and 350 enrolled in the second.

\section{Educational Framework}

In addition to Tanner's Model of Clinical Judgment (Tanner, 2006), which is integrated across the entire curriculum (Disler et al., 2013), this study drew on the principles of narrative pedagogy. Narrative pedagogy in nursing, draws upon film, art and literature to increase students' understanding of the patient's experience (Walsh, 2011). The narrative is used as a stimulus to provoke the exploration of topics, some of which may be uncomfortable to raise like death and dying (Walsh, 2011). 
Across ten teaching weeks, five separate case studies were introduced to students through short vignettes (approximately $5 \mathrm{~min}$ each). The case studies portrayed patients admitted for: an exacerbation of emphysema (history of type II diabetes and mild alcoholism); unstable angina progressing to myocardial infarction; a fractured tibia and fibula following a motorbike accident (history of IV drug dependence); chemotherapy for metastatic cancer and a decision to move to palliative care; and, an upper gastrointestinal bleed (history of bulimia). Patients were from a variety of cultural and socio-economic backgrounds. Semi-professional actors were employed to play the five different patients in the videoed case studies.

To enhance authenticity, not all of the patient responses were scripted. For example, in a scene depicting a nurse having a conversation with a patient about palliative care, the actor supplied her own response regarding any spiritual needs she might have. This helped to avoid stereotyping and allowed the actor some creative control. Examples of nurse/patient dialog are presented in Table 1.

$\mathrm{A}-\mathrm{V}$ vignettes also featured patients' individual idiosyncrasies and demonstrated nursing care and nurse-patient communication in the context of the performance of related skills. The vignettes provided consistency of thecase study delivery across all laboratory classes, reducing individual tutor interpretation. The vignettes were filmed and edited by faculty members and converted into unlisted YouTube clips. The vignettes were complemented with other learning materials such as patient charts and notes and an online $\mathrm{A}-\mathrm{V}$ nursing handover.

\section{Table 1}

Example of nurse-patient interaction portrayed in one of the vignettes.

Case study one-part 2 Nurse-patient dialog

Olivia Bennett has been told she needs to be commenced on insulin to counteract steroid induced hyperglycaemia but she is frightened of needles. Skills taught in this laboratory session include administering subcutaneous injections and monitoring blood glucose levels. Students will also revise the pathophysiology of diabetes mellitus and the pharmacology of hypoglycaemic medications. In part one of this case study, Olivia is admitted for an exacerbation of COPD (emphysema) and students are taught respiratory assessment, oxygen therapy and revise oral medication administration. They also revise the pathophysiology of COPD diseases and the effects of tobacco on the respiratory system.

Olivia- "Dr Brown came, he said something about I've got to have insulin, I don't understand" Nurse- "Did he explain why you need insulin?"

Olivia- "He just said some drug your giving me is mucking up my metformin and I have to have insulin" Nurse-“Dr Brown is talking about prednisolone, it's a steroid.

You've been put on that for your COPD. A side effect is that it causes your liver to release glucose it has stored, so your blood glucose level rises"

Olivia- "Why can't you just give me more metformin?"

Nurse-"You're currently on the largest dose of metformin that we can give you. Any more would damage your kidneys.

So just while you're on the steroid, we need to give you insulin to control your blood glucose levels"

Olivia-"Is it going to hurt?"

Nurse-"It's actually not as painful as the blood sugar testing that we do. It's a really small needle, and it goes straight into ... your belly is a good place. Nowhere near as painful as the finger prick. Is that okay?" Olivia-“Okay then"

Students viewed the vignettes prior to attending laboratory sessions. To further enhance student engagement, the manikins were dressed with the same distinctive props and pajamas worn by the actors in the vignettes. Students use the manikins each session to practice psychomotor skills and communication. Additionally there is a chest pain/ basic life support simulation (medium fidelity) and a role-play simulation during the semester.

\section{Ethical Approval}

The university's Human Research Ethics Committee granted ethical approval for both the use of anonymous student feedback survey (SFS) data, students submit each semester for each subject and a student focus group. Participation in the focus group was voluntary and students were assured that their involvement would have no 
bearing on their academic grades. All participants of the focus group provided written informed consent.

\section{Data Collection}

All students enrolled in the subject were emailed the participant information sheet for consideration. Nine students volunteered to participate in a focus group and were facilitated to explore their responses to the $A-V$ vignettes; the impact these vignettes had on their in-class learning; and, how they interacted with the manikins. The focus group discussion was audio recorded and transcribed verbatim prior to analysis. 143 short answer responses regarding the vignettes were obtained from SFS results. Due to the timing of the SFS and focus group (week twelve in a fourteen week semester), students had only been exposed to four of the five case studies at the time of data collection.

\section{Data Analysis}

Emergent themes were developed through thematic analysis and confirmed through investigator group discussion. Self-selected pseudonyms have been used for responses from the focus group, and anonymous SFS responses have been categorized by the response number from the survey.

Findings

Four clustered themes emerged from the data: Getting past the plastic; knowing what to say; connecting and caring; and, embracing diversity.

\section{Getting Past the Plastic}

A key objective in implementing the vignettes was to increase students' ability to relate to the manikins as the case study patients. To transfer the A-V vignette from the screen to the laboratory we dressed the manikins in the same pajamas the actors wore and included other props such as wigs, reading glasses, tattoos, and jewelry. These visual cues assisted students to overcome the generic patient that manikins can represent:

It [vignettes and props] helps to stop seeing them as a manikin and start seeing them as a patient. So we've heard handover, we've seen them on the video, and now they're here. So it's continuation... I really like it [Jane].

Importantly, students appeared to be more invested in performing the skills properly when they felt connected to the case study patient.

Yeah I know for me in labs lastyear I'd just come in, have a play around with something and like squirt saline across the room and just be an idiot. Whereas now its wait on, this is real, focus!... Charlene is sick, it's like oh let's go. It's real [Lionel].

Increased engagement was also evident in many students who articulated that they became more conscious of the manikins 'feelings' and behaved in a more respectful and thoughtfulway.

The emotions shown [in the patient vignettes] (especially by Diane Coorah) made us more sensitive towards the manikins in class [SFS: 16.8].

In response to the question "what could we add to the case studies to help students relate to the manikins more easily?" several students indicated that they would appreciate more responsiveness from the manikin in the form of speech. During one of the laboratory sessions in which students assess and manage chest pain; tutors were fitted with a headset and answered questions on behalf of the manikin. This activity was well received by students and allowed the manikin (tutor) to respond to specific questions in real time: When the tutor was answering for the manikin but also prompting to keep the simulation moving along, and just doing a bit of that I think helped a lot [Lucinda]. 
assume the voice of the manikin:

I can hold myself together and talk to the dummy but it would be nice to get a response back. Could we do something where we had to be the voice of the manikin one time and next week someone else was? Just to make it more engaging... I love talking and want to know how to interact, because you want them [patients] to be able to trust you [Lorna].

\section{Knowing What to Say}

The patient case study vignettes were generally very well received. Out of the 143 qualitative responses in the SFS that referred to the case studies and manikins, 123 (86\%) were overwhelmingly positive with comments like: I'm not very good at expressing how good these were, but they are definitely worth keeping and using [SFS 17.20]; and, I found the vignettes very helpful this semester and cannot recommend enough that they continue to be used [SFS: 16.21].

The remaining 20 (14\%) responses were ambivalent, with students reporting that they instead drew on their own extensive life experience. Despite not seeing the value for themselves they did concede that they were useful for less experienced students who might not have been in the workforce.

I've been exposed to this sort of thing before and I have a good understanding and empathetic perspective. But I can see how important this would be for the younger students fresh out of school [SFS:

$15: 21]$

The vignettes offered students the opportunity to view the psycho- motor skills they were learning that week portrayed within a montage of symptoms, personalities and situations. This contextualization pro- vided them with not only an introduction to the skill-in-action, but also situated the learning within a particular patient's context and needs (for example, a subcutaneous injection was administered to a patient that feared needles). According to students, being privy to the way experienced nurses approached these issues was invaluable:

The vignettes provided us with a good example of therapeutic communication. They also showed us the way that patients in pain or in some kind of distress may act (thanks to the actors) and this helped in class by allowing us to think about the way the nurses and patients communicated in the video. It also helped to see the nurses in the videos administering medications or giving CPR as when we then practiced these skills we had a good recollection of what kinds of things would be appropriate to say and do [SFS: 16.21].

In the laboratory sessions we found that students often 'parroted' conversations that occurred in the vignettes in early interactions with the manikins and with each other. One student commented: The films were great. At this stage it's easier to model own behaviors after someone else with experience [SFS: 17.15].

This seemed to relieve some of the tension or anxiety in how to respond to the unique needs of a patient while simultaneously undertaking particular nursing skills for the first time. The fact that students often paraphrased the vignette narrative did not seem to lessen the value of the experience for them:

Case study patients had a variety of circumstances. Knowing what to say was helpful as we could practice holistic nursing and not just focus on the skills e.g. giving a needle but also focusing on the patients other needs [SFS: 17.8].

\section{Connecting and Caring}

Each of the five case studies spanned two weeks of face-to-face clinical laboratory classes. Feedback suggested that a fortnight was sufficient for students to 'get to know the patient' and become familiar with the patient's medical, surgical and social history, and treatment. 
you start to get comfortable though there's a new case study [SFS: 17.19].

By the end of semester manystudents had expressed a distinctpreference for one of the patients. Two case study patients in particular were mentioned frequently in feedback, these were Charlene Kennedy a young woman with a history of intravenous drug use admitted for a broken leg after a motorbike accident and Diane Coorah, an Aboriginal woman admitted for chemotherapy and eventually palliation for metastatic breast cancer. I grew quite attached to Diane [SFS: 17.19]. This 'attachment' enabled students to start thinking of the case study patient as a complex individual:

Seeing these videos and seeing patients worried about their families, or verbally aggressive due to pain helped students to consider the greater picture....

Diane Coorah mentions she is worried about herfamily. This then led me to consider why she would focus on them and not herself when she is sick and I discovered that as an Aboriginal lady, she is the matriarch and a lot of people look up to her and rely on her in her family. This helped give me a greater appreciation of the patient as an individual as it showed she had different circumstances to what others had in terms of healthcare due to her spiritual beliefs [SFS: 17.20].

Other reasons that these two patients featured more prominently in students' comments were the timing of the survey and the focus group occurring three quarters of the way through the semester when students were yet to meet the final case study patient. Also, Charlene was verbally aggressive in her first vignette, which made her memorable:

I remember there was that bit where I think she was being a bit sweary and she was in pain or something like that, they were trying to undress her, but then it [the pain] got taken seriously by the nurse on the video and then it was kind of, I don't know it made it more about this is an actual patient, okay they've got this history but they're still like a real patient [Lionel].

Being able to relate to the actor in the vignette as a 'real' person appeared to be linked to students' ability to suspend disbelief. Some students were able to discuss the patient as if they were actual patients, advocating for them and expressing relief when their conditions improved or sadness when they deteriorated. Several students discussed this in terms of feeling connected:

Having case studies allowed me to connect to the patients we are learning about, they are not fictional characters, they are real people who we can see and connect with. This was the greatest aspect of the subject and highly thought provoking and engaging!!! [SFS: 15.5]

\section{Embracing Diversity}

One vignette purposefully exposed students to a patient who frequently used coarse language. Students did not report being shocked or offended; rather they seemed to appreciate an opportunity to openly discuss caring for patients with challenging behaviors.

In the vignette Charlene, the real person talks to the nurse in a pretty agro [aggressive] way. You realise that actually this is what you're going to come across in reality. So it gives you some sense of psychological preparation for what you will be dealing with in the future [Gus].

The decision to make the patient with a history of IV drug abuse verbally aggressive was not made lightly but pragmatically. It allowed the tutors to discuss with students why and how people become addicted to substances; to educate them regarding the increased analgesic tolerance that can occur; to demonstrate deescalation techniques; and, to address prejudiced and judgmental nursing behavior: 
something my tutor said stuck with me "no one just wakes up on a nice Monday morning and decides to take up heroin" This had a huge impact on my somewhat biased views of them [people addicted to substances]. I believe it's something I'd like to carry with me during my nursing career [SFS: 15.9].

Many students had not had the opportunity to meet Aboriginal people. The Diane Coorah case study, although principally focused upon the skills of managing nausea, vomiting, cytotoxic precautions and palliative care was also designed to give the students a glimpse into one Aboriginal woman's life.

I think it's good because it raises awareness. I don't have any friends who are Aboriginal solearning about it [Aboriginal spirituality] in class is helpful because things like that don't come up in everyday life but you need to be aware [Katie].

The multifaceted and rich nature of the case studies provided scope to broaden and deepen students learning experiences. The patient's stories were built in layers, an amalgamation of A-V vignettes, patient handovers as well as written patient notes and charts. One example of layering context was the inclusion of an entry from a fictional social worker in the patient notes discussing Charlene's history of childhood sexual abuse, although this was not alluded to in the vignettes or handover. This 'layering' added to the realism of the case studies, like nursing an actual patient a picture of their overall situation was built from several sources:

You're not telling us what to do or how to think or act, but you're opening up our minds a little bit to think that everyone is still a person and everyone is different and everyone has a story. So it doesn't mean that just because they're sitting in front of you and they take drugs that they're a bad person. Everyone has come from somewhere. I think that having the stories behind the case study patient helps with that [Rory].

\section{Discussion}

The main aim of the current study was to explore student perspectives of the use of vignettes to increase engagement with case study manikins. The participants in the current study articulated an increasing engagement with manikins as a consequence of the vignettes and layered approach to the case studies; however, they also provided advice for future improvements. These centered around providing verbal responses from the manikins. Achieving this with large cohorts of students presents some challenges that will require further consideration (Disler et al., 2013; Rochester et al., 2012).

We believe the use of narrative pedagogy principles to assist the delivery of content in the curriculum has been highly successful at increasing student engagement with the patient case studies and manikins. Exposing students to patient stories allows the tutor and students to discuss different perspectives and arrive at shared understandings of the patient experience (Walsh, 2011). In particular the patient's story can facilitate student's engaging emotionally with the story, which further enhances insight (Haigh and Hardy, 2011; McAllister et al., 2009; Walsh, 2011) and fosters the development of person centered care within students. In the current study this is evident in students feeling invested in the patient case outcome and reporting emotional attachment to some of the case study patients and more solicitous care of the manikins. This is particularly desirable as "kindness, concern, sensitivity, caring, compassion and empathy are known to be the most valued activities of nurses" (Richardson et al., 2015, p. 1). Additionally the patient perspective represents one of the underlying concerns of the evidence based practice movement (Melnyck and Fineout- Overholt, 2005). The main difference with this initiative and existing reports of the use of narrative pedagogy in undergraduate nursing, is that we have written scripts and filmed our own custom narratives rather than drawing on pre-existing resources in order to showcase the particular pathophysiology, psychomotor skills that are aligned to the subject. The ability to start to engage students emotionally when working with manikins in clinical laboratories is exciting and key to development of core nursing competencies, therefore worthy of further consideration.

Introducing a case study where the patient displayed challenging behavior allowed us to explore with students their concerns and expectations for clinical practice, and strategies for resolving issues. Research into managing challenging behavior has identified that it is often decontextualized and oversimplified and framed as a patient's problem (Farrell et al., 2010). Unpacking one of the case study patient's presentation in the context of her social and medical history allowed us to profile the factors contributing to the behavior such as opioid tolerance contributing to the poor management of pain, a social history of childhood abuse leading to a chaotic lifestyle, limited educational 
opportunities and drug use. As evidenced through the data, students were then able to reflect on their own values, assumptions and beliefs regarding people with addictive disorders. Being aware of own attitudes and prejudices can assist with restraining negative judgements of 'difficult' patients and enhance the therapeutic relationship between patient and nurse (Farrell et al., 2010).

Student feedback specifically attested to the usefulness of audio-visual vignettes to provide a modeled approach to interacting with the patient and their family. Negotiating this role of the 'professional' nurse was the core finding in another recent study exploring the impact of simulation on nursing student learning (Walton et al., 2011). Of particular note is the importance of tutors modeling how experienced nurses interact with patients, decreasing students anxiety, and improving their interactions with manikins (Walton et al., 2011).

In summary, the visual, audio and narrative power of carefully designed and filmed vignettes enabled the majority of students who provided feedback to willingly and more authentically engage in the kinesthetic and empathic demands of clinical simulation activities using manikins. By linking realistic and engaging stories to simulation activities, additional layers of realism were incorporated into the classroom activities that improved student engagement and learning overall. Furthermore, a greater development of key competencies and graduate attributes was noted, specifically in relation to communication, person centered care, professional disposition and Indigenous cultural respect. Based on the comments made by the students in the focus group, adding responsive voices to the manikins would further increase the sense of immersion in the clinical scenarios. Future work will incorporate these suggestions from the students and investigate more directly the outcomes for students' learning of specific clinical knowledge and skills.

Limitations/Implications for Education

\section{Limitations}

This study was limited to a single cohort of second year undergraduate nurses. Typically, respondents to student feedback survey open response comments, and students who volunteer for focus groups, are likely to be students who are either highly engaged or have a particular opinion about the subject they want to share. The opinions of other students who did not complete the survey or participate in the focus group are unknown. The student feedback survey and focus group both occurred before the end of semester, which meant that students had only been exposed to four of the five case studies at the time of data collection.

\section{Implications for Education}

Given the mostly positive responses, this was a highly effective method ofincreasingstudentengagementwith manikins. The vignettes once developed have the potential to be reused and deployed across additional subjects where relevant. An array of health issues could be incorporated to create: an introductory version of the patients in foundational first year subjects, and then scripting that patients either deteriorate or represent with new health complications in subsequent years. This would maximize the use of developed resources as well as create an ongoing association for students as they become familiar and develop 'affection' for these patients.

\section{Conclusion}

Originally conceived as a technique to increase students' engagement with manikins in practical laboratory classes, the benefits for students of introducing A-V patient vignettes as a part of multi-layered case studies have been enlightening. In addition to the intended out- comes, more subtle advantages such as allowing students to reflect on their own values and preconceived notions of people from diverse backgrounds were realized. Using narrative pedagogy and increased realism has the potential to enhance students' learning experiences and contribute to thoughtful patient care from our graduate nurses. The key is to provide the 'plastic with personality'.

Acknowledgements

We would like to acknowledge Jacqueline Benson and Joshith Van Houten for their generous contributions to this project. 
Al-Shaer, D., Hill, P.D., Anderson, M.A., 2011. Nurses' knowledge and attitudes regarding pain assessment and intervention. Medsurg Nurs. 20 (1), 7-11.

Disler, R., Rochester, S., Kelly, M.A., White, H., Forber, J., 2013. Delivering a large cohort simulation - beginning nursing students' experience: A pre-post survey. J. Nurse Educ. Pract. 3 (12), 133-142.

Barry, M., Noonan, M., Bradshaw, C., Murphy-Tighe, S., 2012. An exploration of student midwives' experiences of the Objective Structured Clinical Examination assessment process. Nurse Educ. Today 32 (6), 690-694.

Cant, R.P., Cooper, S.J., 2010. Simulation-based learning in nurse education: systematic review. J. Adv. Nurs. 66 (1), 3-15.

Farrell, G.A., Shafiei, T., Salmon, P., 2010. Facing up to "challenging behaviour": a model for training in staff-client interactions. J. Adv. Nurs. 66 (7), 1644-1655.

Fero, L.J., O'Donnell, J.M., Zullo, T.G., DeVito Dabbs, A., Kitutu, J., Samosky, J.T., Hoffman, L.A., 2010. Critical thinking skills in nursing students: comparison of simulation- based performance with metrics. J. Adv. Nurs. 66 (10), 2182-2193.

Foronda, C., Liu, S., Bauman, E.B., 2013. Evaluation of simulation in undergraduate nurse education: an integrative review. Clin. Simul. Nurs. 9 (10), e409-e16.

Guise, V., Chambers, M., Välimäki, M., 2012. What can virtual patient simulation offer mental health nursing education? J. Psychiatr. Ment. Health Nurs. 19 (5), 410-418.

Haigh, C., Hardy, P., 2011. Tell me a story-a conceptual exploration of storytelling in healthcare education. Nurse Educ. Today 31 (4), 408-411.

Jensen, R., 2013. Clinical reasoning during simulation: Comparison of student and faculty ratings. Nurse Educ. Pract. 13 (1), 23-28.

Kameg, K., Howard, V.M., Closhesy, J., Mitchell, A.M., Suresky, J.M., 2010. The impact of high fidelity human simulation on self-efficacy of communication skills. Issues Ment. Health Nurs. 31 (5), 315-323.

McAllister, M., John, T., Gray, M., Williams, L., Barnes, M., Allan, J., Rowe, J., 2009. Adopting narrative pedagogy too improve the student learning experience in a regional Australian university. Contemp. Nurse 32 (1-2), 156165.

McAllister, M., Reid Searle, K., Davis, S., 2013. 'Who is that masked educator? Deconstructing the teaching and learning processes of an innovative humanistic simulation technique. Nurse Educ. Today 33 (12), 1453-1458.

McConville, S.A., Lane, A.M., 2006. Using on-line video clips to enhance self-efficacy to- ward dealing with difficult situations among nursing students. Nurse Educ. Today 26 (3), 200-208.

McLain, N.E., Biddle, C., Cotter, J.J., 2012. Anesthesia clinical performance outcomes: does teaching method make a difference? Am. Assoc. Nurse Anesthetists J. 15 (8), 638-644.

Melnyck, B., Fineout-Overholt, E., 2005. Evidence Based Practice in Nursing and Healthcare. Lippincott, Williams and Wilkins, Philadelphia.

Richardson, C., Percy, M., Hughes, J., 2015. Nursing therapeutics: teaching student nurses care, compassion and empathy. Nurse Educ. Today 35 (5), e1-e5.

Ricketts, B., 2011. The role of simulation for learning within pre-registration nursing education: a literature review. Nurse Educ. Today 31 (7), 650-654.

Rochester, S., Kelly, M., Disler, R., White, H., Forber, J., Matiuk, S., 2012. Providing simula- tion experiences for large cohorts of 1st year nursing students: Evaluating quality and impact. Collegian 19 (3), 117-124.

Schiavenato, M., 2009. Reevaluating simulation in nursing education: beyond the human patient simulator. J. Nurs. Educ. 48 (7), 388-394.

Shin, S., Park, J.-H., Kim, J.-H., 2015. Effectiveness of patient simulation in nursing education: meta-analysis. Nurse Educ. Today 35 (1), 176-182.

Tanner, C.A., 2006. Thinking like a nurse: a research-based model of clinical judgement in nursing. J. Nurs. Educ. 45 (6), 204-211.

Volandes, A., 2007. Medical ethics on film: toward a reconstruction of the teaching of healthcare professionals. J. Med. Ethics 33 (11), 678-680.

Walsh, M., 2011. Narrative pedagogy and simulation: future directions for nursing educa- tion. Nurse Educ. Pract. 11 (3), 216-219.

Walton, J., Chute, E., Ball, L., 2011. Negotiating the role of the professional nurse: the pedagogy of simulation: a 
grounded theory study. J. Prof. Nurs. 27 (5), 299-310.

Yeun, E.J., Bang, H.Y., Ryoo, E.N., Ha, E.-H., 2015. Attitudes to simulation-based learning in nursing students: an application of Q methodology. Nurse Educ. Today 34 (7), 1062-1068. 